\title{
Feeding Behavior in Chicks Given the Same Diet Simultaneously by Two Feeders -Right- and Left-Handed Chicks-
}

\author{
Hiroshi Ueda and Kaori Suehiro
}

Faculty of Agriculture, Ehime University, Matsuyama-shi 790-8566, Japan

\begin{abstract}
Choice feeding has been used to compare likes or dislikes of feedstuff for animals. In the two-choice preference test, it is expected that chicks eat their diets equally from two feeders when they were given the diets with the same palatability. The present experiment was conducted to make sure whether this basic principle is true or not in the short-term choice feeding. When chicks were given the same diet by two feeders, they ate the diet predominantly from one or the other of two feeders for a certain time. Half of chicks ate the diet from right feeders (right-handed chicks) and the other from left feeders (left-handed chicks) so that feed intake from right and left feeders was the same. These results indicated that the favorite feeder position was not confined to one side. Chicks given the choice between diets with the same nutritive value (added with or without $1 \%$ cholesterol) did not show the special preference or aversion to cholesterol, and they initially ate the diet from particular feeders, regardless of the presence or absence of cholesterol. Such undesirable feeding behavior in the choice feeding disappeared as the experiment progressed, or by using older chicks or the acclimation to the choice feeding prior to the experiment.
\end{abstract}

Key words : choice feeding, cholesterol, feeding behavior, right- and left-handed chicks

Diet composition is a major factor influencing the productivity and profitability in animal production. It is well known that deficiency or excess of essential amino acids in the diet adversely affects the growth performance of monogastric animals (Harper et al., 1970). This is true with the most of essential nutrients (Pond et al., 1995). Therefore, in order to avoid the overeating or undereating of nutrients, it is very important to know the requirements of individual nutrient and to establish the feeding standards for animals. It is also essential to evaluate the precise nutritive value of each feed ingredient. Many attempts have been done to accomplish these purposes. Determinations of growth rate, digestibility and concentration of blood, urine, tissue or whole carcass constituents have been frequently used, and these trials have been carried out mainly using ad libitum, restricted or force feeding method.

In addition to the nutritive value of each feedstuff, palatability is also an important factor affecting the utilization of diet. Alfalfa meal is unpalatable to chicken and swine

Received : January 13, 2005, Accepted : February 8, 2005

Correspondence should be addressed to : Dr. Hiroshi Ueda, Faculty of Agriculture, Ehime University, Matsuyama-shi 790-8566, Japan

Tel : 089-946-9819 E-mail : ueda@agr.ehime-u.ac.jp 
due to the presence of saponin, and feeding diets containing large amounts of alfalfa meal depresses egg production or growth rate (Cheeke, 1980). Choice feeding is used to determine the likes and dislikes of feedstuff for animals, in which two or more feeds are simultaneously given to animals. The aversion to a diet containing saponin was observed in the two-choice preference test with chicks (Ueda and Shigemizu, 2001 ; Ueda et al., 2002). Cheeke et al. (1983) compared the sensitivity of four avian species, such as chickens, geese, quails and turkeys, to quinine sulfate, and indicated that geese were more sensitive than others. Cheeke et al. (1978) also reported that the sensitivity of avian species to quinine was extremely low as compared with rats.

In the two-choice preference test, it is expected that animals consume equal amounts of diet from two feeders when the same diet is given by two feeders. However, in practice, the feeding behavior in choice-fed chicks did not necessarily support this basic principle. Most of chicks given the same diet by two feeders for $12 \mathrm{~h}$ exclusively ate their diet from the particular feeder during the first $4 \mathrm{~h}$, after which half of chicks began to eat the diet from the two feeders, but the rest of chicks continued eating the diet from the same feeder (Ueda and Shigemizu, 2001). If such feeding behavior is frequently observed, it may draw the wrong conclusion especially in the short-term choice feeding. For instance, chicks given a choice between diets added with or without $1 \%$ cholesterol preferred the latter over the former during the first $4 \mathrm{~h}$ of the experiment, and the cumulative feed intake of the cholesterol-free diet for $12 \mathrm{~h}$ was higher than that of cholesterol-added diet (Ueda and Shigemizu, 2001). However, it remains an open question to conclude that cholesterol is aversive substance to chicks, because nutritive value was not affected by the cholesterol addition and the differences in feed intake between both diets in the choice feeding were not observed during 4-12 h (Ueda and Shigemizu, 2001).

The present experiment was carried out to elucidate the feeding behavior in chicks given the same diets by two feeders. Feeding response to the two diets added with or without $1 \%$ cholesterol was also examined in the two-choice preference test.

\section{Materials and Methods}

\section{Animals and Diets}

Single Comb White Leghorn male chicks were maintained in wire-mesh cages in a room with constant temperature $\left(30^{\circ} \mathrm{C}\right)$ and continuous lighting. They were raised on a commercial chick starter ration (CP 23\%, ME $3.05 \mathrm{kcal} / \mathrm{g}$ ) during this period. About 1.5 -fold chicks more than those needed for each experiment were selected from the stock on the weight basis and housed individually in metabolism cages about $24 \mathrm{~h}$ before the start of the experiment (Pretest period). At the beginning of the experiment, chicks were weighed again and the necessary number of chicks was distributed to experimental groups so that the initial body weight of each group was as uniform as possible.

In two-choice preference tests, each cage was equipped with two identical feeders, and a drinker was located between these feeders. Feeder positions were fixed during the experiment. Feed intake was measured at 2- or 4-h interval during daytime (0800 to $2000 \mathrm{~h}$ ) and $12 \mathrm{~h}$ interval during the night. After measuring the feed intake, diets were 
added to make up for those consumed by chicks so that two feeders distributed almost equal amounts of diets. Feed spillage was collected by papers placed under the feeders.

As the pretreatments prior to the two-choice preference test, some chicks were freely fed a diet during the pretest period (Satiated), while others were deprived of feed for $12 \mathrm{~h}$ from 2000 to $0800 \mathrm{~h}$ (Fasted). Besides, in order to know the effect of acclimation to the new feeding method, diets were given either by two feeders as did in the two-choice preference test (Acclimated), or by one feeder as usual (Unacclimated) in the pretest period.

The commercial starter ration mentioned above was used as the basal diet. It was finely ground, mixed with water and dried at $45^{\circ} \mathrm{C}$ for $24 \mathrm{~h}$ in a draft oven. Finally, the diet was crumbled to about $1 \mathrm{~mm}$ in diameter. In some experiments, $1 \%$ cholesterol was added to the basal diet at the expense of equal amounts of the basal diet.

Experiments 1-3

All chicks were given the same diet (basal diet) by two feeders in the two-choice preference test after the some treatments mentioned above during the pretest period (Table 1). Twenty chicks were allotted to each trial.

In experiment 1 , feeding response in fasted and satiated chicks without acclimation was compared for $24 \mathrm{~h}$ using nine-d-old chicks. Initial body weight of the fasted and satiated chicks was 75.7 and $82.8 \mathrm{~g}$, respectively. In experiment 2 , the effect of acclimation on feeding behavior was examined for $12 \mathrm{~h}$ using 12-d-old chicks. Initial body weight of acclimated and unacclimated groups was 91.1 and $90.3 \mathrm{~g}$, respectively. In experiment 3 , the effects of age (days old) and fasting on feeding response were tested for $12 \mathrm{~h}$ using 20 -d-old chicks without acclimation. Initial body weight of fasted and satiated groups was 136.4 and $166.4 \mathrm{~g}$, respectively.

Table 1. Summary of feed intake from right and left feeders or Feeders A and $\mathrm{B}^{1)}$

\begin{tabular}{|c|c|c|c|c|c|}
\hline \multirow{3}{*}{ Treatment } & \multirow{3}{*}{$\begin{array}{c}\text { Days } \\
\text { of } \\
\text { age }\end{array}$} & \multicolumn{4}{|c|}{ Feed intake (g/chick) } \\
\hline & & \multicolumn{2}{|c|}{ Feeder } & \multicolumn{2}{|c|}{ Feeder } \\
\hline & & Right & Left & A & $\mathrm{B}$ \\
\hline \multicolumn{6}{|c|}{ Experiment 1 (g/24 h) } \\
\hline Unacclimated Fasted & 9 & $9.0 \pm 0.7$ & $9.4 \pm 0.9$ & $11.2 \pm 0.7$ & $7.2 \pm 0.6^{* *}$ \\
\hline Unacclimated Satiated & & $7.5 \pm 0.9$ & $8.6 \pm 0.9$ & $10.9 \pm 0.6$ & $5.1 \pm 0.5^{* *}$ \\
\hline \multicolumn{6}{|c|}{ Experiment $2(\mathrm{~g} / 12 \mathrm{~h})$} \\
\hline Unacclimated Satiated & 12 & $6.6 \pm 0.6$ & $5.2 \pm 0.7$ & $7.2 \pm 0.5$ & $4.5 \pm 0.6^{* *}$ \\
\hline Acclimated Satiated & & $5.4 \pm 0.5$ & $6.2 \pm 0.6$ & $6.8 \pm 0.5$ & $4.8 \pm 0.5^{* *}$ \\
\hline \multicolumn{6}{|c|}{ Experiment 3 (g/12 h) } \\
\hline Unacclimated Fasted & 20 & $11.2 \pm 1.0$ & $9.6 \pm 1.1$ & $11.8 \pm 1.0$ & $9.1 \pm 1.0^{* *}$ \\
\hline Unacclimated Satiated & & $8.6 \pm 1.1$ & $9.1 \pm 1.3$ & $10.3 \pm 1.2$ & $7.5 \pm 1.0^{* *}$ \\
\hline
\end{tabular}

1) Values are mean $\pm \mathrm{SE}$ for 20 chicks. Feeder from which chicks consumed the diet exclusively during the first $2 \mathrm{~h}$ is referred to as Feeder $\mathrm{A}$, and the other Feeder B. ${ }^{* *}$ Feed intake from Feeders $\mathrm{A}$ and $\mathrm{B}$ is significantly different at $\mathrm{P}<0.01$. 


\section{Experiment 4}

Feeding response in chicks given the choice between the basal diet and a diet containing $1 \%$ cholesterol was studied. First, the nutritive values of both diets were compared in eight-d-old chicks for $5 \mathrm{~d}$ under ad libitum feeding (experiment 4-1). In the two-choice preference tests, eight- (experiment 4-2) and 12-d-old chicks (experiment 4-3) were applied without both of acclimation and fasting. Initial body weight of eight- and 12-d-old chicks was 77.1 and $98.6 \mathrm{~g}$, respectively. The basal and cholesteroladded diets were always distributed from right and left feeders, respectively, and the feeder positions were not changed throughout the experiment. Eight and 14 chicks were allotted to each treatment in ad libitum and choice feeding, respectively.

Statistical Analysis

Data were analyzed statistically by analysis of variance, followed by Tukey's multiple range test (Yoshida, 1975).

\section{Results and Discussion}

In experiment 1 , nine-d-old chicks were given the basal diet by two feeders. As shown in Fig. 1, feed intake from right and left feeders determined at intervals did not differ except for the intake during the first $4 \mathrm{~h}$ in the satiated chicks. Consequently, both fasted and satiated chicks ate the diet equally from right and left feeders during 24-h period (Table 1). However, it appeared from the careful observation that chicks ate the diet predominantly from one feeder immediately after the start of the experiment. Thus, feed intake from two feeders was recalculated by the different perspective as shown in Fig. 2.

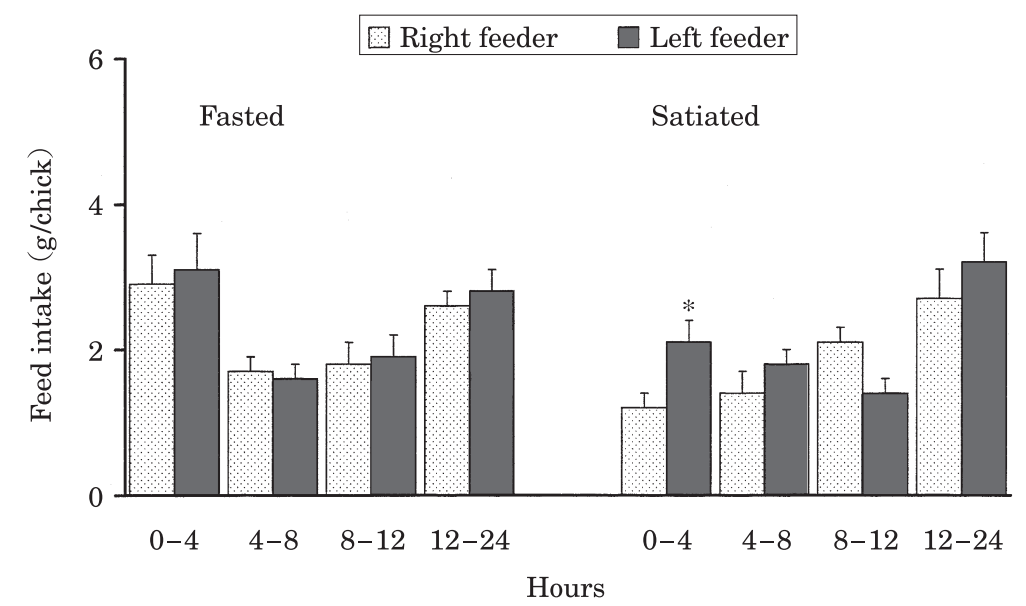

Fig. 1. Feed intake from right and left feeders in fasted and satiated chicks (nine-d-old) given the basal diet simultaneously by two feeders (Experiment 1). Values are mean $\pm \mathrm{SE}$ for 20 chicks. ${ }^{*}$ Feed intake from right and left feeders is significantly different at $\mathrm{P}<0.05$. Fasted chicks were deprived of feed for $12 \mathrm{~h}$ ( 0200 to $0800 \mathrm{~h}$ ) prior to the choice feeding. 


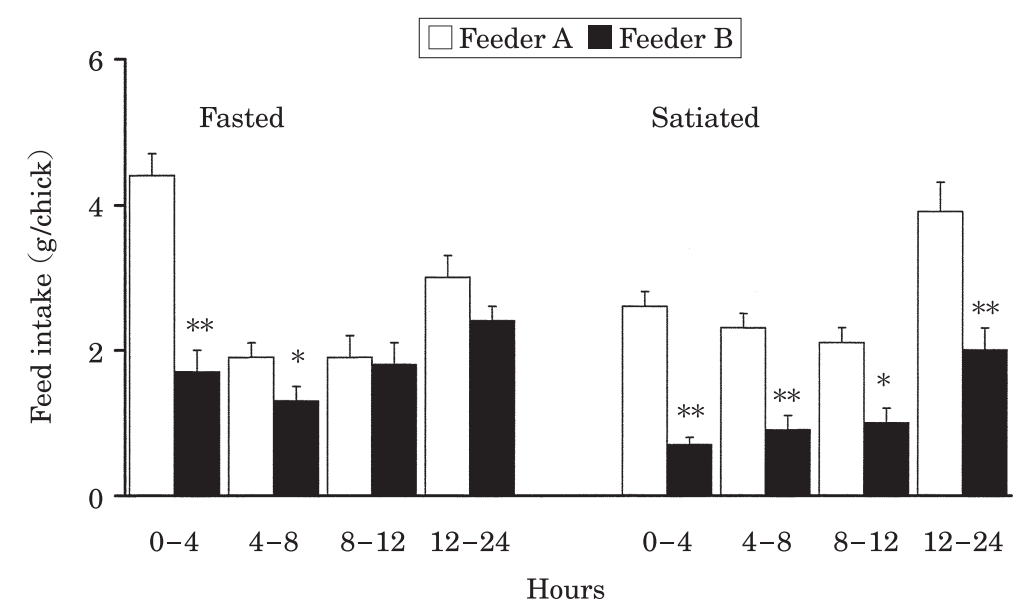

Fig. 2. Feed intake from Feeders $\mathrm{A}$ and $\mathrm{B}$ in fasted and satiated chicks given the basal diet simultaneously by two feeders (Experiment 1). Values are mean \pm SE for 20 chicks. ${ }^{* *}$ and ${ }^{*}$ Feed intake from Feeders $\mathrm{A}$ and $\mathrm{B}$ is significantly different at $\mathrm{P}<0.01$ and 0.05 , respectively. Feeder from which chicks consumed the diet exclusively during the first $2 \mathrm{~h}$ is referred to as Feeder A, and the other Feeder B. Fasted chicks were deprived of feed for $12 \mathrm{~h}(0200$ to $0800 \mathrm{~h}$ ) prior to the choice feeding.

Feeder from which chicks exclusively ate their diet during the first $2 \mathrm{~h}$ was referred to as Feeder A, and the other Feeder B. In contrast to Fig. 1, the significant differences between feed intake from Feeders A and B determined at intervals were observed until 8 and over $24 \mathrm{~h}$ after the start of the experiment in fasted and satiated chicks, respectively. Detailed analysis of data from fasted chicks showed that there were three types of feeding pattern among these chicks (Fig. 3). Four out of 20 chicks ate the diet from Feeder A throughout the test period (Type AA), whereas two chicks switched to Feeder B with time (Type AB). The other 14 chicks selected the diet from Feeder A during the first $4 \mathrm{~h}$, after which they ate their diet equally from the two feeders (Type AO). In fasted group, the number of Type AA was much less than that of Type AO, thereby the differences between feed intake from Feeders A and B determined at intervals disappeared with time. On the other hand, the differences in feed intake remained until $24 \mathrm{~h}$ in satiated groups as shown in Fig. 2, because the number of Type AA (ten chicks) was more than that of Type AO (eight chicks), although data were not shown. However, in both fasted and satiated groups, the cumulative feed intake from Feeder A during $24 \mathrm{~h}$ was higher than that from Feeder B as shown in Table 1.

The results of experiment 1 showed that chicks ate their diet from particular feeders during the early period in the choice feeding when they were given the same diet by two feeders. The position of their favorite feeders was not confined to right or left side, because about half of chicks ate the diet from the right feeders and the other from the left feeders so that feed intake from right and left feeders was the same. The persistence to the particular feeders immediately after the start of the experiment was 


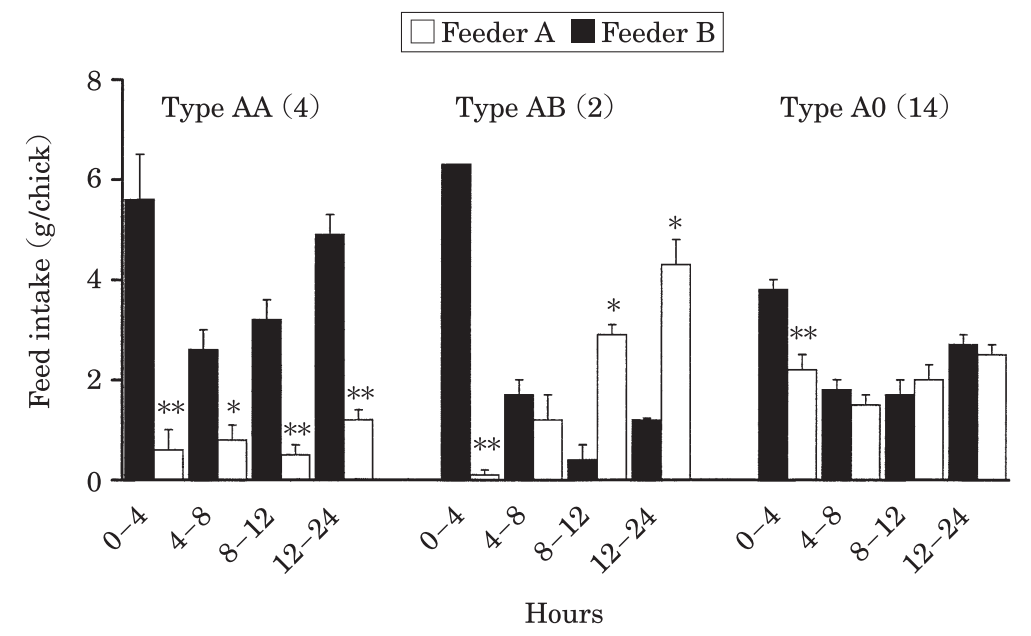

Fig. 3. Different types of feeding pattern in fasted chicks given the basal diet simultaneously by two feeders (Experiment 1). Values are mean \pm SE for 20 chicks. ${ }^{* *}$ and ${ }^{*}$ Feed intake from Feeders $\mathrm{A}$ and $\mathrm{B}$ is significantly different at $\mathrm{P}<0.01$ and 0.05 , respectively. Feeder from which chicks consumed the diet exclusively during the first $2 \mathrm{~h}$ is referred to as Feeder $\mathrm{A}$, and the other Feeder B. Type AA predominantly ate the diet from Feeder A throughout the experiment, type $\mathrm{AB}$ preferred Feeder $\mathrm{B}$ with time, and type $\mathrm{AO}$ ate the diet equally from two feeders except for the first $4 \mathrm{~h}$. Figures in parentheses are number of chicks.

very strong. Even when the favorite feeder was covered by hand or intentionally removed, most of chicks quit feeding instead of switching to the other side of feeder. Thus, each chick was termed right- or left-handed one according to the position of their favorite feeders.

It was surprising that chicks have their own favorite feeder positions to eat the diet, although the reason for this feeding response remained unknown at present. Such feeding response is undesirable in the choice feeding. Therefore, in order to eliminate this behavior, the effect of acclimation to the choice feeding on the unequal feed intake from two feeders was examined in experiment 2 using 12-d-old chicks. Results are given in Fig. 4.

Significant differences between feed intake from Feeders A and B were observed during $0-2 \mathrm{~h}$ and $2-4 \mathrm{~h}$ periods in unacclimated chicks. On the other hand, the differences were only significant during $0-2 \mathrm{~h}$ in acclimated chicks. Thus, the acclimation was effective in reducing the differences between feed intake from Feeders A and B. However, considering the 24-h training period prior to the experiment in acclimated chicks (substantially, feed intake was recorded on the second $d$ of the choice feeding), the fact that feed intake from Feeder A was still higher than that of Feeder B during 0$2 \mathrm{~h}$ period is not ignored. In all experiments, chicks were deprived of feed and water for 15 to 30 min every morning to measure the body weight and feed intake, or to wash drinkers. Thus, it was thought that the time of food deprivation was very short, but 


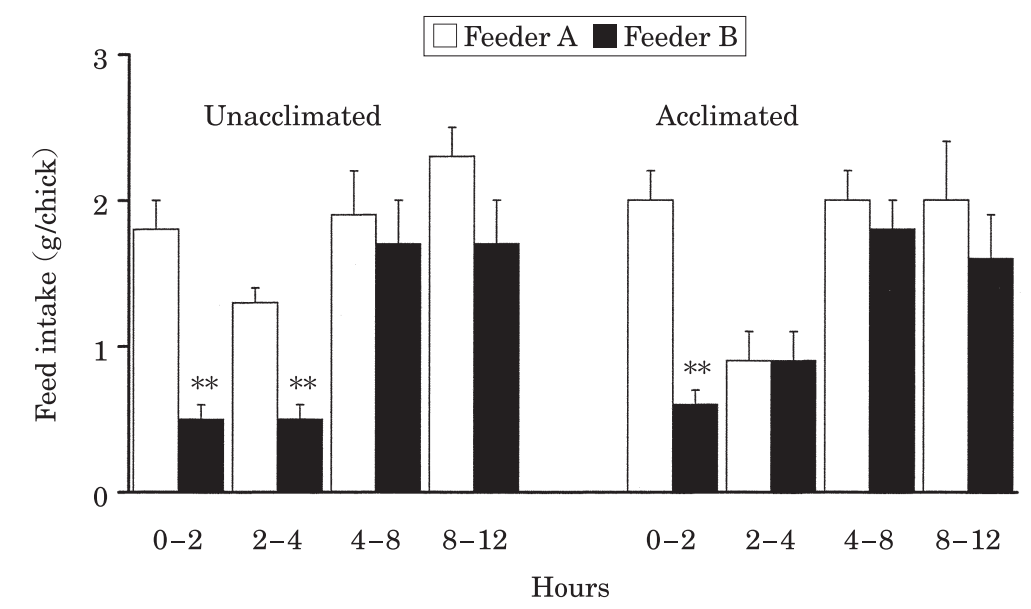

Fig. 4. Feed intake from Feeders $\mathrm{A}$ and $\mathrm{B}$ in unacclimated and acclimated chicks (12-d-old) given the basal diet simultaneously by two feeders (Experiment 2). Values are mean $\pm \mathrm{SE}$ for 20 chicks. ${ }^{* *}$ Feed intake from Feeders $\mathrm{A}$ and $\mathrm{B}$ is significantly different at $\mathrm{P}<0.01$. Unacclimated and acclimated chicks were given the diet by one and two feeders, respectively, for $24 \mathrm{~h}$ prior to the experiment.

even a short-term fasting acted as a stressor and droved chicks to overeat from one feeder. It was observed in the latest experiment that feed intake from two feeders during $2 \mathrm{~h}$ on the second $\mathrm{d}$ of the experiment was the same when chicks were given the continuous access to feed without measuring the body weight in the morning.

In experiment 1, feed intake from Feeder A was always higher than that from Feeder B throughout the 24-h test period in satiated chicks (Fig. 2). On the other hand, feed intake from the two feeders was different only during the first $4 \mathrm{~h}$ (Fig. 4), regardless of a similar experimental procedure (without both of fasting and acclimation). However, there was one difference between the two experiments. That was an age of chicks ; eight- and 12-d-old chicks were used in experiments 1 and 2, respectively. Thus, older chicks were used in experiment 3 to study the effect of age on the feeding behavior in the choice feeding.

Feed intake from Feeders A and B in 20-d-old chicks is illustrated in Fig. 5. The significant differences between feed intake from Feeders A and B were only observed during $0-2 \mathrm{~h}$ after the start of the experiment in both fasted and satiated chicks, regardless of the absence of acclimation. Therefore, it seems likely that the days of age play an important role in the choice feeding.

Table 1 summarizes the feed intake from right and left feeders and that from Feeders $\mathrm{A}$ and $\mathrm{B}$ in experiments 1 to 3 . In all cases, feed intake from right and left feeders was equal, but that from Feeders A and B was significantly different, regardless of acclimation or the use of older chicks. In these experiments, chicks were given the same diet by two feeders. However, the purpose of choice feeding is to compare the palatability or nutritive value of two or more diets. In this regard, it is important to 


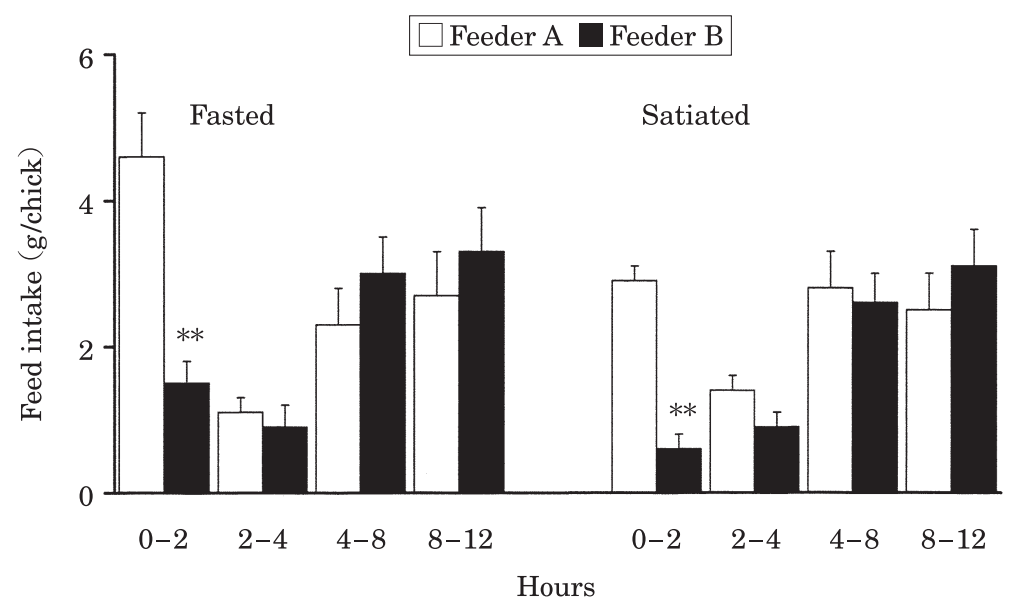

Fig. 5. Feed intake from Feeders A and B in fasted and satiated chicks (20-d-old) given the basal diet simultaneously by two feeders (Experiment 3). Values are mean $\pm \mathrm{SE}$ for 20 chicks. ${ }^{* *}$ Feed intake from Feeders $\mathrm{A}$ and $\mathrm{B}$ is significantly different at $\mathrm{P}<0.01$. Feeder from which chicks consumed the diet exclusively during the first $2 \mathrm{~h}$ is referred to as Feeder $\mathrm{A}$, and the other Feeder B. Fasted chicks were deprived of feed for $12 \mathrm{~h}$ (2000 to $0800 \mathrm{~h}$ ) prior to the choice feeding.

Table 2. Growth performance in chicks fed a diet containing $1 \%$ cholesterol (Experiment $4-1)^{1)}$

\begin{tabular}{|c|c|c|c|c|c|}
\hline \multirow{3}{*}{ Diet } & \multicolumn{4}{|c|}{ Cumulative feed intake } & \multirow{3}{*}{$\frac{\text { Body weight gain }}{5 \mathrm{~d}}$} \\
\hline & $4 \mathrm{~h}$ & $12 \mathrm{~h}$ & $24 \mathrm{~h}$ & $5 \mathrm{~d}$ & \\
\hline & \multicolumn{4}{|c|}{ (g/chick) } & \\
\hline Basal & 3.1 & 9.4 & 15.9 & 81.7 & 42.8 \\
\hline$+1 \%$ cholesterol & 3.0 & 9.1 & 15.1 & 81.0 & 45.3 \\
\hline Pooled SE & 0.2 & 0.4 & 0.5 & 2.3 & 1.3 \\
\hline
\end{tabular}

${ }^{1)}$ Values are means for eight chicks.

know how such feeding behavior affects the experimental results in chicks given a choice between diets with different diet composition. In experiment 4 , chicks were given a choice between the basal diet and a diet containing 1\% cholesterol.

Nutritive value of the two diets was comparable as shown in Table 2 and elsewhere (Ueda and Shigemizu, 1998). However, it was reported that the addition of $1 \%$ cholesterol to a diet containing casein as a protein source caused about two-fold increase in serum cholesterol in chicks (Ueda and Shigemizu, 1998). Cholesterol at this level was also reported to alleviate the growth depression due to saponins in chicks (Ueda and Shigemizu, 1998 ; 2001). Thus, cholesterol has an important physiological action in chicks, even when the added level was as low as $1 \%$ in the diet. 

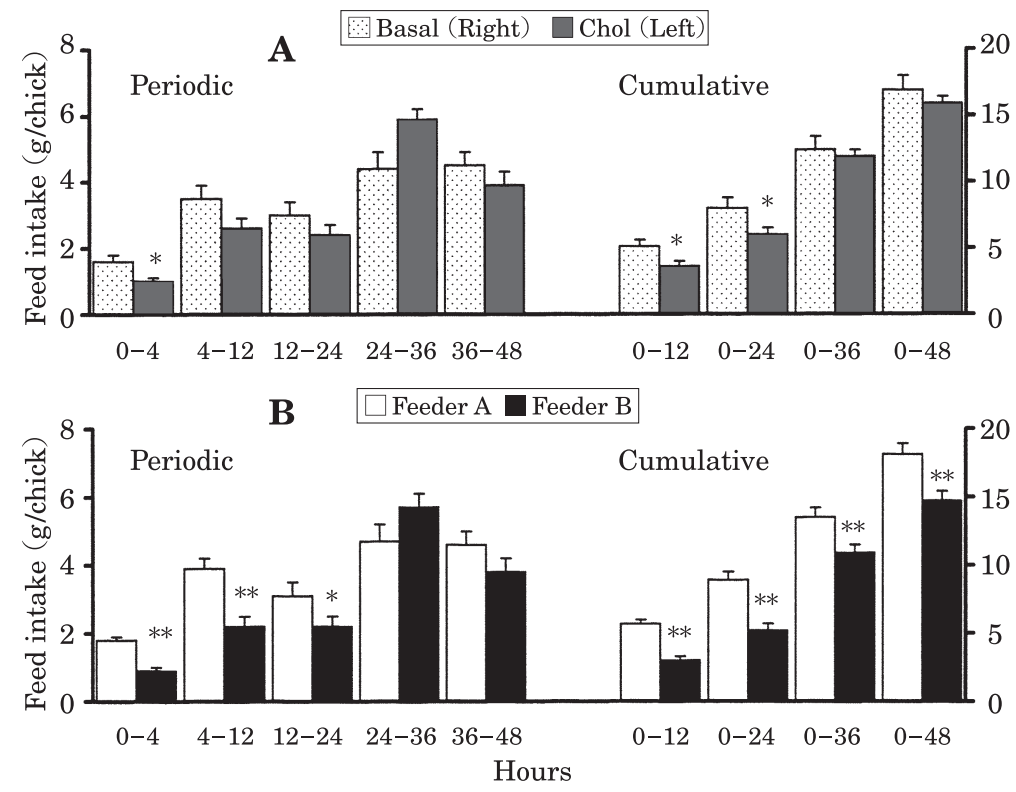

Fig. 6. Feed intake from right and left feeders (A) and from Feeders A and B (B) in satiated chicks (eight-d-old) given a choice between the basal diet and a diet containing 1\% cholesterol (Experiment 4-2). Values are mean \pm SE for 14 chicks. ${ }^{* *}$ and ${ }^{*}$ Feed intake from right and left feeders or that from Feeders $\mathrm{A}$ and $\mathrm{B}$ is significantly different at $\mathrm{P}<0.01$ and 0.05 , respectively. The basal diet was always fed from right feeder. Feeder from which chicks consumed the diet exclusively during the first $2 \mathrm{~h}$ is referred to as Feeder $\mathrm{A}$, and the other Feeder B.

Two preference tests using the cholesterol-added diet were carried out with eightand 12-d-old chicks. The basal diet was always distributed from right feeders and the cholesterol-added diets from left feeders, and the feeder position was not changed throughout the 48-h experiment. Eight-d-old chicks preferred the basal diet (right feeders) to the cholesterol-added diet (left feeders) during the $0-4 \mathrm{~h}$ period (Fig. $6 \mathrm{~A}$ ), and the cumulative feed intake of the basal diet was higher than that of the cholesteroladded diet until $24 \mathrm{~h}$ after the start of the experiment. However, these results did not necessarily indicate that chicks showed the aversion to the cholesterol-added diet, because feed intake of the two diets determined at intervals was equal $4 \mathrm{~h}$ after the start of the experiment (Fig. 6A). More clear-cut results were obtained from experiment using 12-d-old chicks. These chicks ate the equal amounts of basal and cholesteroladded diets from the start of the experiment (Fig. $7 \mathrm{~A}$ ), and there were no significant differences in the cumulative feed intake between the two diets. Considering that the nutritive value of the basal diet and cholesterol-added diet was comparable (Table 2), above results showed that chicks had no special preference or aversion to cholesterol, or they did not differentiate between diets added with or without cholesterol.

When feed intake from Feeders A and B determined at intervals was compared, 

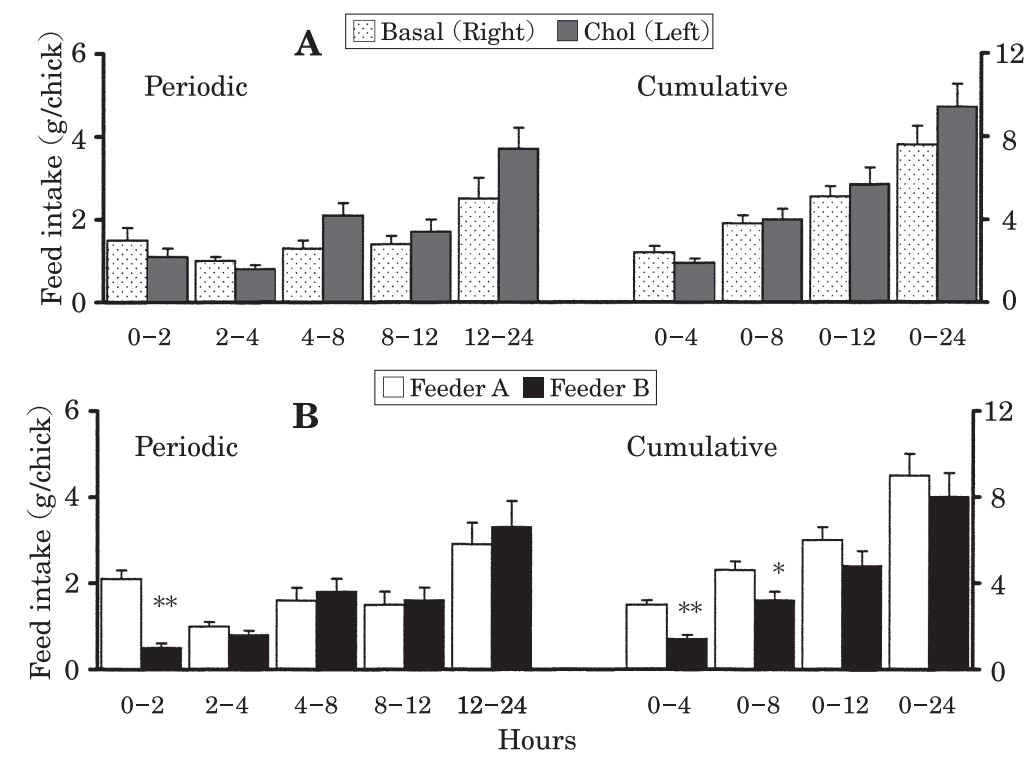

Fig. 7. Feed intake from right and left feeders (A) and from Feeders A and B (B) in satiated chicks (12-d-old) given a choice between the basal diet and a diet containing 1\% cholesterol (Experiment 4-3). Values are mean \pm SE for 14 chicks. ${ }^{* *}$ and ${ }^{*}$ Feed intake from Feeders $\mathrm{A}$ and $\mathrm{B}$ is significantly different at $\mathrm{P}<0.01$ and 0.05 , respectively. The basal diet was always fed from right feeder. Feeder from which chicks consumed the diet exclusively during the first $2 \mathrm{~h}$ is referred to as Feeder A, and the other Feeder B.

eight-d-old chicks continued eating the diet from Feeder A until $24 \mathrm{~h}$ after the start of the experiment (Fig. 6B), and the cumulative feed intake from Feeder A was significantly higher than that from Feeder B throughout the $48 \mathrm{~h}$ of the test period. On the other hand, 12-d-old chicks ate the diet equally from Feeders A and B except for the first $2 \mathrm{~h}$ after the start of experiment (Fig. 7B), thereby the significant differences between cumulative feed intake from the two feeders were only observed until $8 \mathrm{~h}$ in the experiment. These results emphasized again that the days of age was important to equalize the feed intake from two feeders in the choice feeding.

In conclusion, chicks given the same diet by two feeders initially ate their diet from one or the other of two feeders. Since feed intake from right and left feeders was identical, the position of their favorite feeders was not confined to one side. Such feeding behavior is undesirable, because misinterpretation of results is likely to happen. However, fortunately, such feeding behavior disappeared as the experiment progressed, or by using older chicks. The acclimation to choice feeding was also effective. In the present experiment, chicks were given the same diet or diets with the same nutritive value by two feeders. Thus, it remains to elucidate how chicks behave when they are offered the choice between diets with the different palatability or nutritive value. Experiments are in progressed. 


\section{References}

Cheeke PR, Pedersen MW and England DC. Responses of rats and swine to alfalfa saponins. Canadinal Journal of Animal Science, 58 : 783-789. 1978.

Cheeke PR. Biological properties and nutritional significance of legume saponins. In : Leaf Protein Concentrates. (Telek L and Graham HD eds.) pp. 396-414. Avi Publishing. Connecticut. 1980.

Cheeke PR, Powley JS, Nakaue HS and Arscott GH. Feed preference responses of several avian species fed alfalfa meal, high- and low-saponin alfalfa, and quinine sulfate. Canadinal Journal of Animal Science, 63 : 707-710. 1983.

Harper AE, Benevenga NJ and Wohlhueter RM. Effects of ingestion on disproportionate amounts of amino acids. Physiological Reviews, $50: 428-558.1970$.

Pond WG, Church DC and Pond KR. Basic Animal Nutrition and Feeding. 4th ed. John Wiley \& Sons. New Yolk. 1995.

Ueda $\mathrm{H}$ and Shigemizu G. Effects of tea saponin, cholesterol and oils on the growth and feed passage rates in chicks. Animal Science and Technology, $69: 14-21.1998$.

Ueda $\mathrm{H}$ and Shigemizu G. Feeding response to tea saponin in chicks given diet selection. Journal of Poultry Science, $38: 333-342.2001$.

Ueda H, Takagi A, Katou K and Matsumoto S. Feeding behavior in chicks fed tea saponin and quinine sulfate. Journal of Poultry Science, $39: 34-41.2002$.

Yoshida M. Design of Experiments for Animal Husbandry. pp.125-162. Yoken-do. Tokyo. 1975. (in Japanese). 